Abstract 0-010 Table 3 Proportions of documented LVO among patients arriving within 5 hrs of LKW

\begin{tabular}{|c|c|c|c|c|c|}
\hline Characteristic & $\mathrm{N}$ & $\begin{array}{l}\text { Anterior } \\
\text { LVO No. } \\
(\%)\end{array}$ & $\begin{array}{l}\text { P-value } \\
\text { univariate }\end{array}$ & $\begin{array}{l}\text { Adjusted } \\
\text { OR(95\% } \\
\mathrm{Cl})\end{array}$ & $\begin{array}{l}\text { P-value } \\
\text { multivariate }\end{array}$ \\
\hline \multicolumn{6}{|l|}{ Age, years } \\
\hline Age $<80$ & 7,627 & $698(9.2)$ & Reference & & \\
\hline Age $\geq 80$ & 3,848 & $414(10.8)$ & $<0.01$ & $\begin{array}{l}0.85(0.74- \\
0.99)\end{array}$ & 0.03 \\
\hline \multicolumn{6}{|l|}{ Gender } \\
\hline Male & 5,546 & 478 (8.6) & Reference & & \\
\hline Female & 5,929 & $634(10.7)$ & $<0.01$ & $\begin{array}{l}1.07(0.94- \\
1.22)\end{array}$ & 0.31 \\
\hline \multicolumn{6}{|l|}{ Race/ethnicity } \\
\hline White, Non-Hispanic & 9,289 & $924(9.9)$ & Reference & & \\
\hline $\begin{array}{l}\text { Black/African } \\
\text { American }\end{array}$ & 2,186 & $188(8.6)$ & 0.055 & $\begin{array}{l}0.70(0.58- \\
0.84)\end{array}$ & $<0.01$ \\
\hline \multicolumn{5}{|l|}{ Residential Zip Code, } & Median Income \\
\hline$>\$ 50,000$ & 3,651 & $306(8.4)$ & Reference & & \\
\hline$<\$ 50,000$ & 7,824 & $806(10.3)$ & $<0.01$ & $\begin{array}{l}1.06(0.92- \\
1.23)\end{array}$ & 0.43 \\
\hline \multicolumn{6}{|l|}{ Residential Zip Code } \\
\hline Urban & 2,506 & $262(10.5)$ & Reference & & \\
\hline Non-Urban & 8,969 & $850(9.5)$ & 0.14 & $\begin{array}{l}1.00(0.85- \\
1.18)\end{array}$ & 0.95 \\
\hline \multicolumn{6}{|l|}{ Presenting Hospital } \\
\hline $\begin{array}{l}\text { Comprehensive/ } \\
\text { Thrombectomy- } \\
\text { Capable }\end{array}$ & 6,770 & $906(13.4)$ & Reference & & \\
\hline Primary & 4,705 & $206(4.4)$ & $<0.01$ & $\begin{array}{l}0.32(0.27- \\
0.38)\end{array}$ & $<0.01$ \\
\hline \multicolumn{6}{|l|}{ Baseline Ambulation } \\
\hline Independent & 9,504 & $976(10.3)$ & Reference & & \\
\hline with Assistance & 589 & $38(6.5)$ & $<0.01$ & $\begin{array}{l}0.42(0.30- \\
0.57)\end{array}$ & $<0.01$ \\
\hline \multicolumn{6}{|l|}{ Stroke Severity } \\
\hline NIHSS $\leq 5$ & 6,971 & $181(2.6)$ & Reference & & \\
\hline NIHSS $>5$ & 4,504 & $931(20.7)$ & $<0.01$ & $\begin{array}{l}6.81(5.89- \\
7.88)\end{array}$ & $<0.01$ \\
\hline
\end{tabular}

Abstract 0-010 Table 4 MT rates among early arrival patients with a LVO

\begin{tabular}{|c|c|c|c|c|c|}
\hline Characteristic N & $\begin{array}{l}\text { MT- } \\
\text { treated } \\
\text { No. (\%) }\end{array}$ & $\begin{array}{l}\text { P-value } \\
\text { univariate }\end{array}$ & $\begin{array}{l}\text { Adjusted } \\
\text { OR(95\% } \\
\text { Cl) }\end{array}$ & $\begin{array}{l}\text { P-value } \\
\text { multivariate }\end{array}$ & \\
\hline \multicolumn{6}{|l|}{ Age, years } \\
\hline Age $<80$ & 698 & $476(68.2)$ & Reference & & \\
\hline Age $\geq 80$ & 414 & $250(60.4)$ & $<0.01$ & $\begin{array}{l}0.71(0.53- \\
0.95)\end{array}$ & 0.02 \\
\hline \multicolumn{6}{|l|}{ Gender } \\
\hline Male & 478 & $318(66.5)$ & Reference & & \\
\hline Female & 634 & $408(64.4)$ & 0.45 & & \\
\hline \multicolumn{6}{|l|}{ Race/ethnicity } \\
\hline White, Non-Hispanic & 924 & $602(65.2)$ & Reference & & \\
\hline
\end{tabular}

\begin{tabular}{|c|c|c|c|c|c|}
\hline Black/African & 188 & $124(66.0)$ & 0.83 & & \\
\hline \multicolumn{6}{|l|}{ American } \\
\hline \multicolumn{6}{|c|}{ Residential Zip Code, } \\
\hline \multicolumn{6}{|l|}{ Median Income } \\
\hline$>\$ 50,000$ & 306 & $204(66.7)$ & Reference & & \\
\hline$<\$ 50,000$ & 806 & $522(64.8)$ & 0.55 & & \\
\hline \multicolumn{6}{|c|}{ Residential Zip Code } \\
\hline \multicolumn{6}{|c|}{ Population Density } \\
\hline Urban & 262 & $158(60.3)$ & Reference & & \\
\hline Non-Urban & 850 & $568(66.8)$ & 0.05 & $\begin{array}{l}1.47 \text { (1.07- } \\
2.02)\end{array}$ & 0.02 \\
\hline \multicolumn{6}{|c|}{ Presenting Hospital } \\
\hline \multicolumn{6}{|c|}{ Stroke Certification } \\
\hline Comprehensive/ & 906 & $594(65.6)$ & Reference & & \\
\hline \multicolumn{6}{|l|}{ Thrombectomy- } \\
\hline \multicolumn{6}{|l|}{ Capable } \\
\hline Primary & 206 & $132(64.1)$ & 0.69 & & \\
\hline \multicolumn{6}{|c|}{ Baseline Ambulation } \\
\hline Independent & 976 & $666(68.2)$ & Reference & & \\
\hline with Assistance & 38 & $22(57.9)$ & 0.18 & $\begin{array}{l}0.56(0.28- \\
1.11)\end{array}$ & 0.09 \\
\hline \multicolumn{6}{|l|}{ Stroke Severity } \\
\hline NIHSS $\leq 5$ & 181 & 70 (38.7) & Reference & & \\
\hline NIHSS $>5$ & 931 & $656(70.5)$ & $<0.01$ & $\begin{array}{l}4.81(3.41- \\
6.83)\end{array}$ & $<0.01$ \\
\hline
\end{tabular}

Conclusions Black stroke patients underwent MT less frequently than Whites, likely in part due to longer times from LKW to hospital arrival and a lower rate of documented aLVO. Further studies are needed to assess whether extending the MT time window and more aggressive LVO screening protocols mitigate this disparity.

Disclosures A. Wallace: None. D. Gibson: 2; C; iSchemaView, Medtronic, Siemens. K. Asif: None. D. Sahlein: 2; C; Medtronic, Microvention, Stryker, Phenox. 3; C; Medtronic. S. Warach: None. T. Malisch: None. M. Lamonte: None.

\section{0-011 OUTCOMES OF MECHANICAL THROMBECTOMY IN STROKE PATIENTS PRESENTING WITH LOW ASPECTS IN THE EARLY AND LATE WINDOW-INSIGHT FROM STAR}

${ }^{1} E$ Almallouhi*, 'S Al Kasab, 'Z Hubbard, ${ }^{1} G$ Porto, ${ }^{2} \mathrm{~A}$ Alawieh, ${ }^{1} \mathrm{R}$ Chalhoub, ${ }^{1} \mathrm{E}$ Bass, ${ }^{3} \mathrm{P}$ Jabbour, ${ }^{4} \mathrm{R}$ Starke, ${ }^{5} \mathrm{~S}$ Wolfe, ${ }^{6} \mathrm{~A}$ Arthur, ${ }^{7} \mathrm{I}$ Maier, ${ }^{2} \mathrm{~J}$ Grossberg, ${ }^{8} \mathrm{~A}$ Rai, ${ }^{9} \mathrm{M}$ Park, ${ }^{10} \mathrm{~J}$ Mascitelli, ${ }^{11} \mathrm{M}$ Psychogios, ${ }^{12} \mathrm{R}$ De Leacy, ${ }^{13} \mathrm{D}$ Raper, ${ }^{14} \mathrm{~T}$ Dumont, ${ }^{15} \mathrm{M}$ Levitt, ${ }^{16} \mathrm{~A}$ Polifka, ${ }^{17} \mathrm{~J}$ Osbun, ${ }^{18} \mathrm{R}$ Crosa, ${ }^{19} \mathrm{~J} \mathrm{Kim},{ }^{20} \mathrm{~W}$ Casagrande, ${ }^{21} \mathrm{M}$ Mokin, ${ }^{22} \mathrm{C}$ Matouk, ${ }^{23} \mathrm{~A}$ Shaban, ${ }^{24}$ I Fragata, ${ }^{25} \mathrm{~A}$ Yoo, ${ }^{26} \mathrm{~A}$ Spiotta. ${ }^{1}$ Medical University of South Carolina, Charleston, SC; ${ }^{2}$ Emory University, Atlanta, GA; ${ }^{3}$ Thomas Jefferson University, Philadelphia, $P A ;{ }^{4}$ University of Miami, Miami, FL; ${ }^{5}$ Wake Forest University, Winston-Salem, NC; ${ }^{6}$ University of Tennessee Health Science Center, Memphis, TN; ${ }^{7}$ University Medical Center Göttingen, Göttingen, Germany; ${ }^{8}$ West Virginia University, Morgantown, WV: ${ }^{9}$ University of Virginia, Charlottesville, VA; ${ }^{10}$ University of Texas Health Science Center at San Antonio, San Antonio, TX; ${ }^{11}$ University of Basel, Basel, Switzerland; ${ }^{12}$ Mount Sinai Hospital, New York, NY; ${ }^{13}$ Baylor College of Medicine, Houston, $T X_{;}{ }^{14}$ University of Arizona, Tuscon, $A Z_{i}$ ${ }^{15}$ University of Washington, Seattle, WA; ${ }^{16}$ University of Florida, Gainesville, FL; ${ }^{17}$ Washington University in St Louis, St Louis, MO; ${ }^{18}$ Endovascular Neurological Center, Montevideo, Uruguay; ${ }^{19}$ Chonnam National University Hospital, Gwangju, Korea, Republic of; ${ }^{20}$ Hospital Juan Fernandez, Buenos Aires, Argentina; ${ }^{21}$ University of South Florida, Tampa, FL; ${ }^{22}$ Yale University/Yale-New Haven Hospital, New Haven, $C T ;{ }^{23}$ University of Iowa, lowa City, IA; ${ }^{24}$ Hospital São José, Centro Hospitalar Lisboa Central, Lisboa, Portugal;

${ }^{25}$ Texas Stroke Institute, Dallas-Fort Worth, TXi ${ }^{26}$ Neurosurgery, Medical University of South Carolina, Charleston, SC

10.1136/neurintsurg-2021-SNIS.11 
Introduction Limited data is available about the outcomes of mechanical thrombectomy (MT) in stroke patients presenting with a large core infarct. We aim to investigate the safety and efficacy of MT in patients with large vessel occlusion and Alberta Stroke Program Early CT Score (ASPECTS) of 2-5.

Methods Data from Stroke Thrombectomy and Aneurysm Registry (STAR), which combined the prospectively maintained databases of 28 thrombectomy-capable stroke centers in the US, Europe, and Asia, was interrogated. We identified thrombectomy patients presenting with an occlusion in the Internal carotid artery (ICA) or M1 segment of the middle cerebral artery (MCA). Multivariable regression analysis was performed to assess factors associated with favorable 90-day outcome (modified Rankin scale 0-3), including interaction terms between ASPECTS 2-5 and receiving MT in the extended window ( $\geq 6$ hours from symptom-onset).

Results Among MT patients who presented with ICA or M1 occlusion, 2132 had ASPECTS $\geq 6$ and 213 patients had ASPECTS 2-5. Patients in the low ASPECTS group were younger ( 70 vs. 72 years old, $\mathrm{P}=0.003$ ) and more likely to present with an ICA occlusion $(47.9 \%$ vs. $28.8 \%, \mathrm{P}<0.001)$ compared to patients with ASPECTS $\geq 6$. At 90 days, mRS $0-3$ was observed in $36.6 \%$ of the patients who presented with ASPECTS 2-5 (42\% in patients who had successful recanalization and $10.8 \%$ in patients who had failed recanalization, $\mathrm{P}=0.001$ ) (figure 1). Lower ASPECTS and presenting in the extended window were both associated with worse 90- day outcomes after controlling for potential confounders, without significant interaction between these two factors.

Conclusion More than one in three patients presenting with ASPECTS (2-5) may achieve favorable 90-day functional outcome following MT. Favorable outcome was 4 times higher in low ASPECTS patients who had successful recanalization. The effect of low ASPECTS on 90-day outcome did not differ in patients presenting in the early versus extended MT window. Disclosures E. Almallouhi: None. S. Al Kasab: None. Z. Hubbard: None. G. Porto: None. A. Alawieh: None. R. Chalhoub: None. E. Bass: None. P. Jabbour: None. R. Starke: None. S. Wolfe: None. A. Arthur: None. I. Maier: None. J. Grossberg: None. A. Rai: None. M. Park: None. J. Mascitelli: None. M. Psychogios: None. R. De Leacy: None. D. Raper:
None. T. Dumont: None. M. Levitt: None. A. Polifka: None. J. Osbun: None. R. Crosa: None. J. Kim: None. W. Casagrande: None. M. Mokin: None. C. Matouk: None. A. Shaban: None. I. Fragata: None. A. Yoo: None. A. Spiotta: 1; C; Stryker, Penumbra, and Medtronic. 2; C; Penumbra, Stryker, Cerenovus, Terumo.

\section{0-012 EVIDENCE OF ARTERIAL COLLAPSE IN A HUMAN BRAIN MODEL AND IN-VIVO WITH ASPIRATION THROMBECTOMY}

${ }^{1} Y$ Liu*$^{*}{ }^{2} \mathrm{D}$ Gebrezgiabhier, ${ }^{1}$ J Arturo Larco, 'S Madhani, ${ }^{1} \mathrm{~A}$ Shahid, ${ }^{1} \mathrm{R}$ Kadivel, ${ }^{1} \mathrm{~W}$ Brinjikji, 'D Kallmes, 'L Savastano. 'Mayo Clinic, Rochester, MN; ${ }^{2}$ UC Berkeley, Berkeley, $C A$

\subsection{6/neurintsurg-2021-SNIS.12}

Introduction New generation aspiration catheters have larger bore size and are equipped with stronger aspiration pumps to provide higher aspiration force. We analyzed the mechanical response of cerebral arteries under aspiration thrombectomy in preclinical models and characterized the features affecting the likelihood and severity of arterial collapse.

Materials and Methods Fresh whole human brains $(n=9)$ were harvested and connected to a saline flow system with physiologically representative pressure and flow rates. Aspiration thrombectomy ( $\mathrm{n}=168,54$ in M1, 52 in M2, and 62 in BA) was carried out with commercially available suction catheters (56 using ACE64, 55 using ACE68, and 57 using Sofia 6F) connected to a pump (Gomco 405, $-650 \mathrm{mmg}$ ), under different blood perfusion pressures $(85,58$, and $0 \mathrm{mmhg})$. Arterial wall responses were recorded via direct transluminal observation. A total of 168 tests over nine brains were carried out with the arterial wall response graded and analyzed. Then, aspiration thrombectomy was performed with a Sofia 5F catheter connected to pump (Gomco 405, -650 mmhg) in vivo in the abdominal aorta of adult new Zealand white rabbit $(n=3)$ and size of the arterial lumen continuously evaluated by intravascular optical coherence tomography (OCT).

Results Arterial collapse was observed in both experimental models. In the brain model, arterial walls collapsed in $88 \%$ of

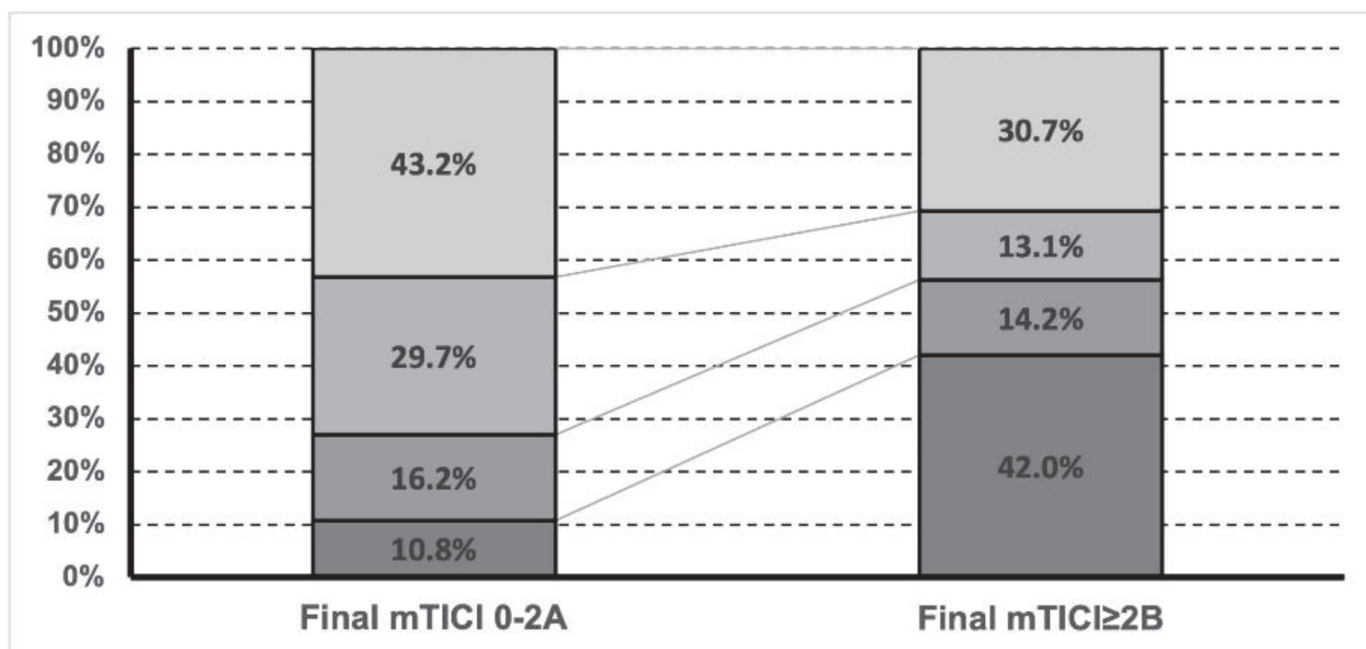

口mRS 0-3 amRS 4 amRS 5 amRS 6 